\title{
Efficiency of Rubidium Marking in Aedes albopictus (Diptera: Culicidae): Preliminary Evaluation on Persistence of Egg Labeling, Survival, and Fecundity of Marked Female
}

\author{
Rafael Maciel-de-Freitas, Jaylei Monteiro Gonçalves*, Ricardo Lourenço-de-0 liveira/+
}

Laboratório de Transmissores de Hematozoários, Instituto Oswaldo Cruz-Fiocruz, Av. Brasil 4365, 21040-900 Rio de Janeiro, RJ, Brasil *Departamento de Química, Instituto Nacional de Controle e Qualidade e Saúde-Fiocruz, Rio de Janeiro, RJ, Brasil

Rubidium chloride ( $\mathrm{RbCl}$ ) has been used for the study of vector biology and behavior, although the efficacy of marking, egg production, and survivorship of marked females have been poorly studied. Four concentrations of $\mathrm{RbCl}$ were tested, among which $0.025 \mathrm{M}$ was the best for marking Aedes albopictus: more than $80 \%$ of egg batches of females fed once with blood containing $\mathrm{RbCl}$ were marked; Rb-marked egg batches, interspersed with non marked ones were recovered until 61 days after a blood meal containing RbCl followed by non marked meals; $\mathrm{RbCl}$ was essentially detected in the abdomen of marked females, whose egg production and survivorship did not differ from non marked ones, at least in the three weeks following the Rb-marked blood meal.

Key words: Aedes albopictus - rubidium chloride - marking - persistence - survival

A wide variety of marking techniques has been used in the evaluation of biological parameters of insects of medical and agricultural importance (Service 1993, Hagler \& Jackson 2001). Conceptually, the markers must last in the animal, their application must not affect its behavior, and the released insects must become thoroughly mixed among the native population (Southwood 1978). One of the most frequently used trace element marker for insects is the chloride form of rubidium ( $\mathrm{RbCl}) . \mathrm{Rb}$ is an alkali metal, non-toxic to plants, insects and other animals (Kimsey \& Kimsey 1984, Anderson et al. 1990). There are several techniques to apply $\mathrm{Rb}$ on insects: it may be sprayed on host plants to mark phytophagous insects (Berry et al. 1972, Kipp \& Lonergan 1992); added to the water in which larvae are reared (Holbrook et al. 1991, Solberg et al. 1999) or to artificial diets (Hayes \& Reed 1989, Knight et al. 1989, Pearson et al. 1989, Johnson \& Reeves 1995); or injected into vertebrate hosts and subsequently detected in the eggs of haematophagous insects blood-fed on them, since the imbibed alkali metal is incorporated into ovarian follicles and accumulates in the insect eggs (Holbrook 1995).

$\mathrm{Rb}$ has been largely used as marker for the study of blood-feeding and oviposition behaviors of vectors, such as midges and mosquitoes (Kimsey \& Kimsey 1984, Anderson et al. 1990, Holbrook 1995, Hodgson et al. 2001). Reiter et al. (1995) and Reiter (1996) developed a method of monitoring dispersal of Aedes aegypti during oviposition in

Financial support: $\mathrm{CNPq}$

${ }^{+}$Corresponding author. Fax. +55-21-2573.4468. E-mail: lourenco@ioc.fiocruz.br

Received 14 June 2004

Accepted 10 November 2004
Puerto Rico by labeling their eggs with Rb. These authors released gravid mosquitoes previously blood-fed on a solution of RbCl in citrated pig blood. Honório et al. (2003) also estimated flight ranges of mosquitoes in an endemic dengue area in Rio de Janeiro (Lourenço-de-Oliveira et al. 2002) monitoring eggs of released Ae. aegypti and Ae. albopictus previously fed with defibrinated sheep blood containing $\mathrm{RbCl}$.

The concentration of $\mathrm{RbCl}$ in the blood taken by the insects has considerably varied among experiments and the effectiveness of concentration of this metal as a marker, and the persistence of egg labeling during female lifetime have never been evaluated. Besides, the possible adverse effects of $\mathrm{Rb}$ in survival and egg production in mosquitoes have been poorly studied (Solberg et al. 1999). Moreover, the amount of $\mathrm{Rb}$ labeling each egg in an egg batch probably varies among batches, since it depends on the amount of $\mathrm{Rb}$ incorporated in the ovaries. The minimum number of $\mathrm{Rb}$-marked eggs necessary for the marker to be detected in an egg batch has never been accessed.

The present paper aims to address the ideal blood concentration of $\mathrm{RbCl}$ for egg labeling in Ae. albopictus females and the efficacy of marking in terms of duration in egg labeling in females fed with a single blood meal containing the marker, egg production and female survivorship. Besides, the permanence of $\mathrm{Rb}$ in the body of mosquitoes is also analyzed.

Ae. albopictus mosquitoes used in the experiments were $\mathrm{F}_{2}$ females from a laboratory colony derived from adults collected in Jacarepaguá, Rio de Janeiro (22 $55^{\circ} \mathrm{S}$ $43^{\circ} 18^{\prime} \mathrm{W}$ ). Mosquitoes were maintained at $26 \pm 2^{\circ} \mathrm{C}$ and $70 \pm 10 \%$ humidity. Larvae were fed with fish food (Tetramin $\left.{ }^{\circledR}\right)$ and reared according to Consoli and Lourenço-de-Oliveira (1994). Four groups of 50 females were isolated from males on the fourth day after emergence and transferred to cylindrical cages $(9 \mathrm{~cm}$ height, 9 
$\mathrm{cm}$ diameter). Adults were provided with sucrose solution from emergence to one day before blood feeding. Defibrinated sheep blood containing one of the following concentrations of $\mathrm{RbCl}$ was simultaneously offered to 56 days old females in a feeding apparatus (Rutledge et al. 1964): $0.015 \mathrm{M}, 0.025 \mathrm{M}, 0.25 \mathrm{M}$ and $0.50 \mathrm{M}$. After blood feeding, fully engorged females from each treatment were counted and isolated in labeled cylindrical plastic vial (6.5 $\mathrm{cm}$ height, $2.5 \mathrm{~cm}$ diameter) containing a moistened cotton overlaid with filter paper as substrate for oviposition on the bottom and closed on top by mosquito net. They were daily observed and provided with sucrose solution during 15 days. The eggs laid by each female in this period were counted and subsequently examined in an atomic emission spectrophotometer. The ideal concentration of $\mathrm{RbCl}$ was considered according to the number of fully engorged females per cage and to the ratio of egg batches containing $\mathrm{Rb}$ marked-eggs over the produced eggs.

For the detection of $\mathrm{Rb}$, samples were heated to $100^{\circ} \mathrm{C}$ in $1 \mathrm{ml} 65 \%$ nitric acid. After complete evaporation of the acid, $1 \mathrm{ml}$ of distilled water was added and each sample was examined in an atomic emission spectrophotometer in a wavelength of $780 \mathrm{~nm}$ (ICP OPTIMUN 3300 DV Perkin Elmer). Absorbance values of $\mathrm{RbCl}$ free egg batches (control) ranged between 676.97 and 1558.24. Mean absorbance value and standard errors for egg batches from the control group were used to estimate a confident interval $(\alpha=$ $0.01)$. Egg batches of the experimental group whose absorbance values were higher than the limit calculated above were considered as positive for $\mathrm{RbCl}$ labeling.

No Ae. albopictus female was fully engorged in the two highest $\mathrm{RbCl}$ concentrations $(0.25 \mathrm{M}$ and $0.50 \mathrm{M})$, which provides indirect evidence that the amount of rubidium present in the dilution can alter the attractiveness of females to a blood-meal. The best performance was observed for the $0.025 \mathrm{M} \mathrm{RbCl}$ concentration: $34 \%$ of females took a complete blood meal and the marker was detected in $83 \%$ of egg batches, a frequency twice higher than the observed for those females fed with blood containing $0.015 \mathrm{M} \mathrm{RbCl}$ (Table I). Accordingly, the concentration of $0.025 \mathrm{M} \mathrm{RbCl}$ diluted in an artificial blood meal was considered the ideal and thus used in the experiment described bellow. Coincidentally, this concentration was the same used in the field works by Reiter et al. (1995) and Honório et al. (2003).

In the subsequent experiment, a blood meal was offered to two groups of $100 \mathrm{~F} 2 \mathrm{Ae}$. albopictus females on the fourth day of emergence, consisting of defibrinated sheep blood (a) containing $0.025 \mathrm{M} \mathrm{RbCl}$ ( $\mathrm{RbCl}$ group) or (b) free of this metal (control group). Females were treated as above. Fully engorged females in each treatment were counted, numbered and isolated in cylindrical plastic vial, and daily provided with sucrose solution as above. $\mathrm{RbCl}$ free blood meals were offered to females belonging to both treatments in intervals of around five days. The number of eggs laid per female was counted on the fourth day after each blood feeding and each egg batch was individually analyzed for $\mathrm{Rb}$ making as described above. Survivorship was measured by checking daily the number of dead females. Carcasses of recently dead females were divided into two parts (head plus thorax, and abdomen) and analyzed for the search of $\mathrm{Rb}$.

A total of 37 and 52 Ae. albopictus females were fully engorged with blood containing $0.025 \mathrm{M} \mathrm{RbCl}$ and free of $\mathrm{RbCl}$, respectively. The persistence of Rb marking in subsequent ovipositions after a unique artificial blood feeding with $0.025 \mathrm{M} \mathrm{RbCl}$ is in Table II. A total of $31 \mathrm{Ae}$. albopictus females (83.8\%) laid Rb-marked eggs at least once during their lifetime, and $21(56.8 \%)$ of them laid Rbmarked eggs in two or more occasions. Eleven females laid Rb-marked eggs only after one or more non-marked egg batches. Around 75\% ( $\mathrm{N}=27)$ females laid $\mathrm{Rb}$-marked egg batches in the first 15 days after taken the marked blood meal. Twenty-one Ae. albopictus females were alive by day 31 , and $10(47.6 \%)$ of them laid marked eggs between one and two months after the single blood meal with $\mathrm{RbCl} 0.025 \mathrm{M}$. The longest persistence of $\mathrm{Rb}$-marked egg batches was reported for female number 27 , which laid marked eggs on day 61, after laying one non-marked and eight Rb-marked egg batches. Seven females (18.9\%) that were fully engorged with a Rb-blood meal have never laid marked eggs. Honório et al. (2003) reported that $9 \%$ of Ae. albopictus fed with blood containing $\mathrm{RbCl}$ failed in laying labeled eggs in the following five days. Thus $\mathrm{Rb}$ marking is not uniform among females fed with a solution of a given concentration of $\mathrm{RbCl}$ in blood. Furthermore, the alternance of Rb-marked and non-marked egg batches in the same female seems to be an evidence that the distribution of $\mathrm{Rb}$ in its abdomen is not homogeneous, particularly among ovaryoles and developing ovules of $A e$. albopictus. Holbrook (1995) showed that the ratio of Rbmarked midges decreased with time in 14 days after taking the marked blood meal.

The longest survival recorded for females belonging to the control and $\mathrm{RbCl}$ groups were 87 and 59 days, respectively. The mortality rate of non-marked females was similar to that of $\mathrm{Rb}$-marked females until around day 22 following the Rb-marked blood meal (Fig. 1). From this

TABLE I

Number of Aedes albopictus females engorged on four solutions of rubidium chloride ( $\mathrm{RbCl}$ ) in defibrinated sheep blood, and that laid marked eggs at the laboratory

\begin{tabular}{lccc}
\hline RbCl concentration & $\begin{array}{c}\text { Number of } \\
\text { engorged females }\end{array}$ & $\begin{array}{c}\text { Number of } \\
\text { females that oviposed }\end{array}$ & $\begin{array}{c}\text { Number of females that laid Rb-marked } \\
\text { eggs among those that oviposited }\end{array}$ \\
\hline $0.015 \mathrm{M}$ & $9 / 50$ & 8 & $3(37.5 \%)$ \\
$0.025 \mathrm{M}$ & $17 / 50$ & 12 & $10(83.3 \%)$ \\
$0.25 \mathrm{M}$ & $-/ 50$ & - & - \\
$0.50 \mathrm{M}$ & $-/ 50$ & - & - \\
\hline
\end{tabular}


day on, mortality in the $\mathrm{Rb}$-group increased. Camparing the two survival curves using the Log-rank test (Kleinbaum 1996), that emphasizes differences in the middle to final section of the curve, significant difference is found $(\log -\mathrm{Rank}=6.6, \mathrm{df}=1, \mathrm{P}<0.01)$. This result suggests that $\mathrm{Rb}$-marking may decrease survivorship of mosquitoes, but only after three weeks of taking the blood meal containing the metal. Estimating the $95 \%$ confident interval of the survival curves (Kleinbaum 1996), we found that the two curves overlap, indicating that time to $50 \%\left(\mathrm{LT}_{50}\right)$ and $90 \%\left(\mathrm{LT}_{90}\right)$ mortality for the $\mathrm{RbCl}$ and control groups were not statistically different: 31 and 40 days and 53 and 61 days, respectively, which are in the same range of values found in other laboratory survival studies of Ae. albopictus (e.g. Hylton 1969: 41 and 60 days, respectively).

The mean number of eggs laid by females of $\mathrm{RbCl}$ group was slightly higher than that of females belonging to the control group, except on day 41 (Fig. 2). The mean number of eggs for each batch collected every four days after each blood meal was 42.2 for the $\mathrm{RbCl}$ group and 33.5 for the control. Gubler (1970) found that the mean number of eggs laid by Ae. albopictus in the first and most productive gonothrophic cycle ranged from 51.8 and 71.8 depending on the blood source. The averages of total eggs laid by each Ae. albopictus during our entire experiment were 255 and 204 for the $\mathrm{RbCl}$ and control group, respectively, which are smaller than that found by Gubler and Bhattacharya (1971), i.e. 283 eggs.

$\mathrm{Rb}$ was detected at the same time in the head plus thorax and abdomen of only two Ae. albopictus fed once with blood containing the marker. On the other hand, $\mathrm{Rb}$ was found in the abdomen of 27 females (73\%). Eight females laid $\mathrm{Rb}$-marked eggs once or more, although the marker has not been detected in the respective carcasses.

TABLE II

Oviposition of 37 Aedes albopictus females fed once on a solution containing $0.025 \mathrm{M}$ rubidium chloride (RbCl) in defibrinated sheep blood (day 0 ) and subsequently fed on $\mathrm{RbCl}$ free blood every 4-5 days until dying (gray area) at the laboratory

\begin{tabular}{|c|c|c|c|c|c|c|c|c|c|c|c|c|c|}
\hline \multicolumn{14}{|c|}{ Days after blood feeding containing $\mathrm{RbCl}$} \\
\hline Female & 4 & 9 & 14 & 18 & 25 & 31 & 37 & 41 & 46 & 51 & 56 & 61 & 66 \\
\hline 1 & $\times$ & - & - & $\times$ & - & & & & & & & & \\
\hline 2 & $\times$ & $x$ & + & - & - & $\times$ & & & & & & & \\
\hline 3 & - & + & $\times$ & + & - & $\times$ & - & $x$ & & & & & \\
\hline 4 & - & + & 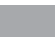 & & & & & & & & & & \\
\hline 5 & - & - & - & + & + & + & - & & & & & & \\
\hline 6 & $\times$ & - & + & + & & & & & & & & & \\
\hline 7 & + & + & - & - & - & - & - & & & & & & \\
\hline 8 & $\times$ & + & + & - & - & & & & & & & & \\
\hline 9 & $\times$ & + & + & - & - & & & & & & & & \\
\hline 10 & - & + & + & - & - & - & & & & & & & \\
\hline 11 & $\times$ & & & & & & & & & & & & \\
\hline 12 & - & - & - & $\times$ & - & + & - & & & & & & \\
\hline 13 & $\times$ & $\times$ & - & - & & & & & & & & & \\
\hline 14 & + & - & $x$ & $\times$ & & & & & & & & & \\
\hline 15 & - & - & + & - & & & & & & & & & \\
\hline 16 & + & + & - & $\times$ & - & $\times$ & & & & & & & \\
\hline 17 & + & + & - & - & 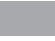 & 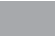 & & & & & & & \\
\hline 18 & - & + & - & $\times$ & - & $\times$ & & & & & & & \\
\hline 19 & - & 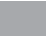 & & & & & & & & & & & \\
\hline 20 & $\times$ & $\times$ & - & $x$ & $\times$ & $\times$ & $\times$ & & & & & & \\
\hline 21 & $\times$ & + & & & & & & & & & & & \\
\hline 22 & $x$ & - & - & + & & & & & & & & & \\
\hline 23 & + & + & $\times$ & + & - & - & - & - & & & & & \\
\hline 24 & + & + & $\times$ & + & - & - & - & & & & & & \\
\hline 25 & $x$ & + & - & + & $\times$ & + & + & + & + & - & + & - & \\
\hline 26 & $\times$ & $\times$ & $\times$ & - & $\times$ & $\times$ & & & & & & & \\
\hline 27 & $x$ & + & + & + & $\times$ & $\times$ & + & + & + & + & - & + & \\
\hline 28 & + & + & + & - & - & & & & & & & & \\
\hline 29 & $x$ & + & + & + & + & + & + & - & + & - & & & \\
\hline 30 & + & + & - & + & 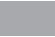 & & & & & & & & \\
\hline 31 & + & + & + & + & - & + & - & - & - & + & & & \\
\hline 32 & - & + & + & + & - & + & - & 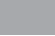 & 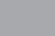 & 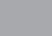 & & & \\
\hline 33 & - & + & + & $\times$ & + & + & - & - & & & & & \\
\hline 34 & + & $\times$ & $\times$ & & & & & & & & & & \\
\hline 35 & $\times$ & $\times$ & + & $\times$ & + & + & - & - & - & + & & & \\
\hline 36 & $x$ & + & - & + & + & + & + & - & - & & & & \\
\hline 37 & $\times$ & $\times$ & $\times$ & - & $\times$ & $\times$ & $\times$ & $\times$ & & & & & \\
\hline
\end{tabular}

+: Rb-labeled egg batch; -: unmarked egg batch; $\times$ : no egg 
Thus, $\mathrm{Rb}$-marking was identified in 35 cases (95\%), be in the abdomen or eggs. $\mathrm{Rb}$ was detected in the abdomen of 5 females whose eggs were negative for the marker.

Fig. 3 shows that the absorbance values in the atomic emission spectrophotometer vary according to the number of RbCl-marked eggs per batch among females fed with blood containing $\mathrm{RbCl} 0.025 \mathrm{M}$. The absorbance values for egg batches with low number of eggs (ranging from 6 to 60) were low, while they were essentially high in batches containing from 100 to 160 eggs. However, the analysis of some batches with intermediate amount of eggs (from 61 to 90 eggs) exhibited absorbance values with high amplitude, ranging from 500 to $70,000 \mathrm{~nm}$. The $R^{2}$ value $\left(R^{2}=0.6106\right)$ of the linear fit to the data indicates that absorbance values were influenced in a moderate degree by other parameters than the number of eggs in each egg batch produced by Ae. albopictus once fed with $\mathrm{Rb}$-marked blood. Rb-labeled eggs were detectable even in a batch containing only 6 eggs.

This paper supports that $\mathrm{RbCl}$ is a useful and reliable marker for the study of biological and behavioral parameters of haematophagous species, there including mosquitoes such as Ae. albopictus, since the marking may persist in several ovipositions following a single marked

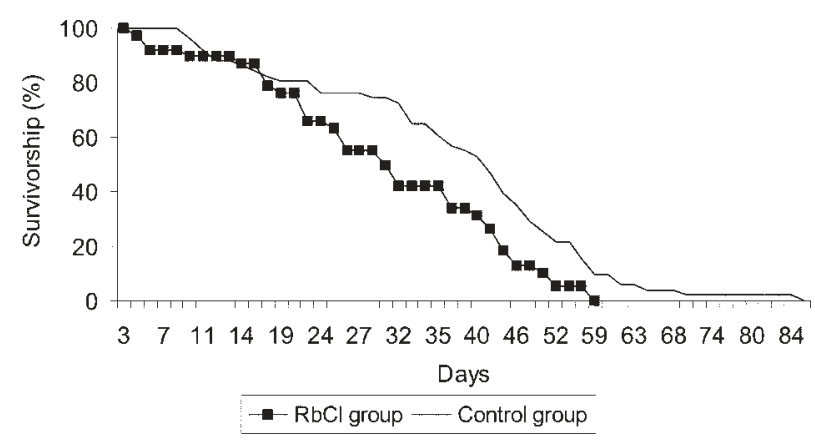

Fig. 1: survivorship of Aedes albopictus females fed on day zero on a solution containing $0.025 \mathrm{M}$ rubidium chloride $(\mathrm{RbCl})$ in sheep blood $(\mathrm{N}=37)$ or on rubidium free sheep blood (control, $\mathrm{N}=52)$, and subsequently fed on $\mathrm{RbCl}$ free blood every 4-5 days until dying at the laboratory.

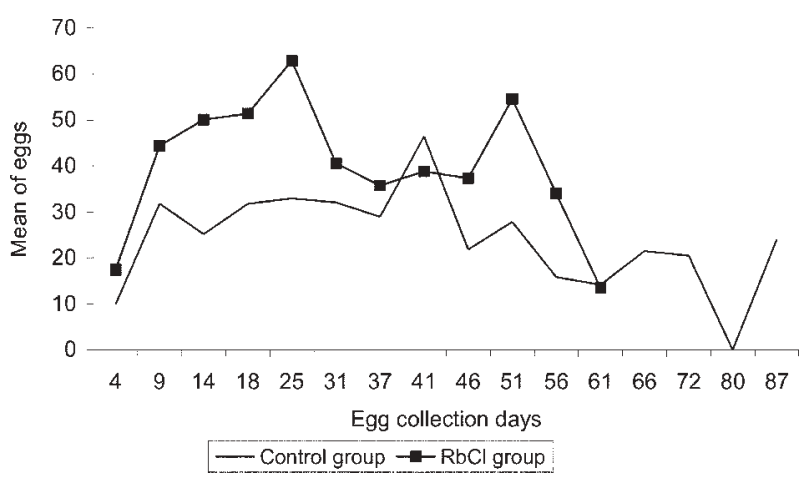

Fig. 2: mean number of eggs laid by Aedes albopictus females after a blood meal with $0.025 \mathrm{M}$ rubidium chloride $(\mathrm{RbCl})$ (on day zero) compared to a control group that took $\mathrm{RbCl}$ free blood. Females of both groups were subsequently fed on $\mathrm{RbCl}$ free blood every 4-5 days until dying at the laboratory.

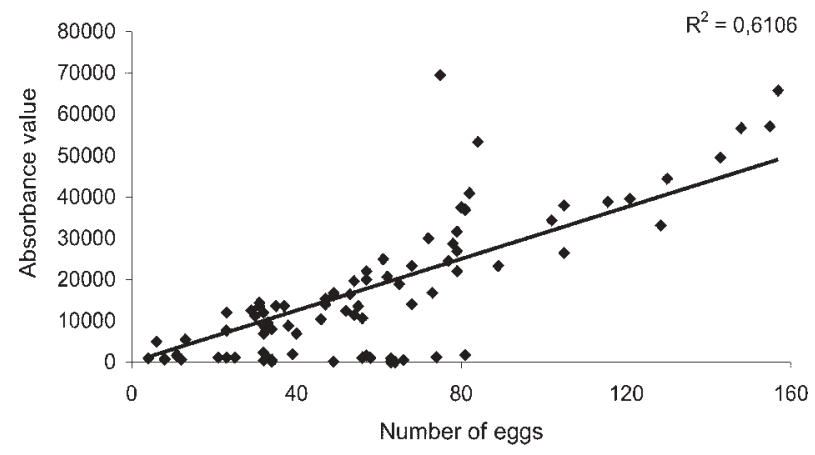

Fig. 3: relationship of absorbance values of rubidium chloride-marked egg batches analyzed in the atomic emission spectrophotometer and the number of eggs per batch of Aedes albopictus females fed with defibrinated sheep blood containing $0.025 \mathrm{M} \mathrm{RbCl}$ at the laboratory.

blood meal and does not affect egg production and survival, at least during three weeks following the labeled blood meal.

\section{ACKNOWLEDGEMENTS}

To Mariangela Ziccardi for the critical reviewing the manuscript and to Cláudia Codeço for the help in the statistical analyses.

\section{REFERENCES}

Anderson RA, Edman JD, Scott TW 1990. Rubidium and cesium as host blood-markers to study multiple blood-feeding by mosquitoes (Diptera: Culicidae). J Med Entomol 27: 999-1001.

Berry WL, Stimmann MW, Wolf WW 1972. Marking of native phytophagous insects with rubidium: a proposed technique. Ann Entomol Soc Am 65: 236-238.

Consoli RAGB, Lourenço-de-Oliveira R 1994. Principais Mosquitos de Importância Sanitária no Brasil, Fiocruz, Rio de Janeiro, 225 pp.

Gubler DJ 1970. Comparison of reproductive potentials of Aedes (Stegomyia) albopictus Skuse and Aedes (Stegomyia) polynesiensis marks. Mosq News 30: 201-209.

Gubler DJ, Bhattacharya NC 1971. Observations on the reproductive history of Aedes (Stegomyia) albopictus in the laboratory. Mosq News 31: 356-359.

Hagler JR, Jackson CG 2001. Methods for marking insects: current techniques and future prospects. Annu Rev Entomol 46: 511-543.

Hayes JL, Reed KG 1989. Using rubidium-treated artificial nectar to label adults and eggs of Heliothis virescens (Lepidoptera: Noctuidae). Environ Entomol 18: 807-810.

Hodgson JC, Spielman A, Komar N, Krahforst CF, Wallace GT, Pollack RJ 2001. Interrupted blood-feeding by Culiseta melanura (Diptera: Culicidae) on European starlings. J Med Entomol 38: 59-66.

Holbrook FR 1995. Rubidium in female Culicoides variipennis sonorensis (Diptera: Ceratopogonidae) after engorgement on a rubidium-treated host. J Med Entomol 32: 387-389.

Holbrook FR, Belden RP, Bobian RJ 1991. Rubidium for marking adults of Culicoides variipennis (Diptera: Ceratopogonidae). J Med Entomol 28: 246-249.

Honório NA, Silva WC, Leite PJ, Gonçalves JM, Lounibos LP, Lourenço-de-Oliveira 2003. Dispersal of Aedes aegypti and Aedes albopictus (Diptera: Culicidae) in an urban endemic dengue area in the state of Rio de Janeiro, Brazil. Mem Inst Oswaldo Cruz 98: 191-198. 
Hylton AR 1969. Studies on longevity of adult Eretmapodites chrysogaster, Aedes togoi and Aedes (Stegomyia) albopictus females (Diptera: Culicidae). J Med Entomol 6: 147-149.

Johnson PC, Reeves RM 1995. Incorporation of the biological marker rubidium in gypsy moth (Lepidoptera: Lymantriidae) and its trasfer to the predator Carabus nemoralis (Coleoptera: Carabidae). Environ Entomol 24: 46-51.

Kimsey RB, Kimsey PB 1984. Identification of arthropod blood meals using rubidium as a marker: a preliminary study. $J$ Med Entomol 21: 714-719.

Kipp LR, Lonergan GC 1992. Comparison of topically applied rubidium chloride and fluorescent dye markers on survival and recovery of field-released male spruce budworm moths. Can Entomol 124: 325-333.

Kleinbaum DG 1996. Survival Analysis: a Self-learning Text, Springer Verlag, New York, 324 pp.

Knight AL, Hull LA, Rajotte EG, Fleischer SJ 1989. Labeling tufted apple bud moth (Lepidoptera: Tortricidae) with rubidium: effect on development, longevity, and fecundity. Ann Entomol Soc Am 82: 481-485.

Lourenço-de-Oliveira R, Honório NA, Castro MG, Schatzmayr HG, Miagostovich MP, Alves JCR, Silva WC, Leite PJ, Nogueira RMR 2002. Dengue virus type 3 isolated from
Aedes aegypti in the municipality of Nova Iguaçu, state of Rio de Janeiro. Mem Inst Oswaldo Cruz 97: 799-800.

Pearson AC, Ballmer GR, Sevacherian V, Vail PV 1989. Interpretation of rubidium marking levels in beet armyworm eggs (Lepidoptera: Noctuidae). Environ Entomol 18: 844849.

Reiter P 1996. Oviposition et dispersion d'Aedes aegypti dans l'environnement urbain. Bull Soc Path Ex 89: 120-122.

Reiter P, Amador MA, Anderson RA, Clark GG 1995. Short report: dispersal of Aedes aegypti in an urban area after blood feeding as demonstrated by rubidium-marked eggs. Am J Trop Med Hyg 52: 177-179.

Rutledge LC, Ward RA, Gould DJ 1964. Studies on the feeding response of mosquitoes to nutritive solutions in a new membrane feeder. Mosq News 24: 407-419.

Service MW 1993. Mosquito Ecology - Field Sampling Methods, Chapman \& Hall, London, 988 pp.

Solberg VB, Bernier L, Schneider I, Burge R, Wirtz RA 1999. Rubidium marking of Anopheles stephensi (Diptera: Culicidae). J Med Entomol 36: 141-143

Southwood TRE 1978. Ecological Methods with Particular Reference to the Study of Insect Populations, Chapman \& Hall, London, 524 pp. 
